九州大学学術情報リポジトリ

Kyushu University Institutional Repository

\title{
Endothermic energy transfer: A mechanism for generating very efficient high-energy phosphorescent emission in organic materials
}

\section{Adachi, Chihaya}

Center for Photonics and Optoelectronic Materials (POEM), Department of Electrical Engineering and the Princeton Materials Institute, Princeton University

Kwong, Raymond C.

Universal Display Corporation

Djurovich, Peter

Baldo, Marc. A.

Center for Photonics and Optoelectronic Materials (POEM), Department of Electrical Engineering and the Princeton Materials Institute, Princeton University

他

http://hdl. hand le. net/2324/19449

出版情報: Applied Physics Letters. 79 (13), pp.2082-2084, 2001-09-24. American Institute of Physics

バージョン :

権利関係: Copyright 2001 American Institute of Physics. This article may be downloaded for personal use only. Any other use requires prior permission of the author and the American Institute of Physics. 


\title{
Endothermic energy transfer: A mechanism for generating very efficient high-energy phosphorescent emission in organic materials
}

\author{
Chihaya Adachi, Raymond C. Kwong, ${ }^{\text {a) }}$ Peter Djurovich, ${ }^{\text {a) }}$ Vadim Adamovich, \\ Marc A. Baldo, Mark E. Thompson, ${ }^{\text {b) }}$ and Stephen R. Forrest ${ }^{\mathrm{C})}$ \\ Center for Photonics and Optoelectronic Materials (POEM), Department of Electrical Engineering, \\ Princeton University, Princeton, New Jersey 08544
}

(Received 21 June 2001; accepted for publication 16 July 2001)

\begin{abstract}
Intermolecular energy transfer processes typically involve an exothermic transfer of energy from a donor site to a molecule with a substantially lower-energy excited state (trap). Here, we demonstrate that an endothermic energy transfer from a molecular organic host (donor) to an organometallic phosphor (trap) can lead to highly efficient blue electroluminescence. This demonstration of endothermic transfer employs iridium(III)bis(4,6-di-fluorophenyl)-pyridinato- $N, C^{2}{ }^{\prime}$ )picolinate as the phosphor. Due to the comparable energy of the phosphor triplet state relative to that of the $4,4^{\prime}$ $N, N^{\prime}$-dicarbazole-biphenyl conductive host molecule into which it is doped, the rapid exothermic transfer of energy from phosphor to host, and subsequent slow endothermic transfer from host back to phosphor, is clearly observed. Using this unique triplet energy transfer process, we force emission from the higher-energy, blue triplet state of the phosphor (peak wavelength of $470 \mathrm{~nm}$ ), obtaining a very high maximum organic light-emitting device external quantum efficiency of $(5.7 \pm 0.3) \%$ and a luminous power efficiency of $(6.3 \pm 0.3) \mathrm{lm} / \mathrm{W}$. (C) 2001 American Institute of Physics.
\end{abstract}

[DOI: 10.1063/1.1400076]

Energy transfer from a conductive host to a luminescent dopant can result in high external quantum efficiencies in organic thin-film light-emitting devices. For example, we have recently demonstrated high-efficiency green and red organic electrophosphorescent devices which harvested both singlet and triplet excitons, leading to internal quantum efficiencies $\left(\eta_{\text {int }}\right)$ approaching $100 \% .^{1-5}$ In these cases, high efficiencies were obtained by energy transfer from both the host singlet and triplet states to the phosphor triplet, or via direct trapping of charge on the phosphor, thereby harvesting up to $100 \%$ of the excited states. These transfers entail a resonant, exothermic process. As the triplet energy of the phosphor increases, it becomes less likely to find an appropriate host with a suitably high-energy triplet state. The very large excitonic energies required of the host also suggest that this material layer may not have appropriate energy-level alignments with other materials used in an OLED structure, hence, resulting in a further reduction in efficiency. To eliminate this competition between the conductive and energy transfer properties of the host, a route to efficient blue electrophosphorescence may involve the endothermic energy transfer from a near-resonant excited state of the host to the higher triplet energy of the phosphor. ${ }^{6,7}$ Provided that the energy required in the transfer is not significantly greater than the thermal energy, this process can be very efficient.

Here, we demonstrate blue electrophosphorescence using energy transfer from a conductive organic host to the iridium complex: iridium(III)bis[4,6-di-fluorophenyl)pyridinato- $N, C^{2}$ ]picolinate (FIrpic). ${ }^{8}$ The introduction of

\footnotetext{
${ }^{a}$ Universal Display Corporation, 375 Phillips Blvd., Ewing, NJ 08618.

b) Department of Chemistry, University of Southern California, Los Angeles, Los Angeles, CA 90089.

${ }^{c)}$ Electronic mail: forrest@princeton.edu
}

the electron withdrawing fluorine complex results in an increase of the triplet exciton energy and, hence, a blueshift of the phosphorescence compared with that of $\operatorname{Ir}(\mathrm{ppy})_{3}$. We obtained a maximum external quantum electroluminescent (EL) efficiency $\left(\eta_{\text {ext }}\right)$ of $(5.7 \pm 0.3) \%$ and a luminous power efficiency $\left(\eta_{p}\right)$ of $(6.3 \pm 0.3) \mathrm{lm} / \mathrm{W}$, representing a significant improvement of the efficiencies compared with the blue fluorescent emitters reported to date. ${ }^{9-11}$

Figure 1(a) shows photoluminescent (PL) spectra of three different iridium-based phosphors, bis(2-phenylpyridinato- $\left.N, C^{2 \prime}\right)$ iridium(acetylacetonate) $\quad\left[\mathrm{ppy}_{2} \operatorname{Ir}(\mathrm{acac})\right]$, bis $\left[4\right.$, 6-di-fluorophenyl)-pyridinato- $\left.N, C^{2 \prime}\right]$ iridium(acetylacetonate) $[\mathrm{FIr}(\mathrm{acac})]$, and FIrpic, demonstrating a spectral shift with ligand modification. The presence of the heavy metal iridium results in strong spin-orbit coupling and metal ligand charge transfer, allowing for rapid intersystem crossing of excitons into the radiative triplet manifold of the ligand. ${ }^{8}$ All three complexes give high photoluminescent efficiencies of $\Phi_{\mathrm{pl}}=0.5-0.6$ in fluid solution. With introduction of fluorine atoms into the 4,6-positions in 2-phenylpyridine, the triplet excited state experiences a blueshift of $\sim 40 \mathrm{~nm}$ in the PL peak FIr(acac) as compared with the green emitting $\mathrm{ppy}_{2} \operatorname{Ir}(\mathrm{acac})$. Furthermore, replacement of the acetylacetonate ligand of $\operatorname{Frr}(\mathrm{acac})$ with picolinate (i.e., FIrpic) resulted in an additional $\sim 20 \mathrm{~nm}$ blueshift.

Organic light-emitting devices were grown on a glass substrate precoated with a $\sim 130$-nm-thick indium-tin-oxide (ITO) layer with a sheet resistance of $\sim 20 \Omega / \square$. Prior to organic layer deposition, the substrate was degreased with solvents and cleaned for $5 \mathrm{~min}$ by exposure to an UV-ozone ambient, after which it was immediately loaded into the evaporation system. With a base pressure of $\sim 4 \times 10^{-8}$ Torr, the organic and metal cathode layers were grown successively without breaking vacuum using an in vacuo mask ex- 


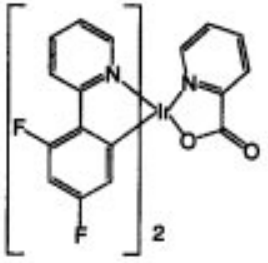

(a)

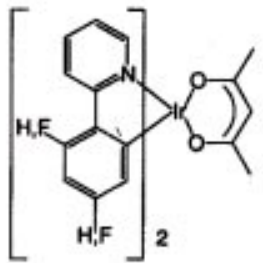

(b) $\mathrm{F}$, (c) $\mathrm{H}$
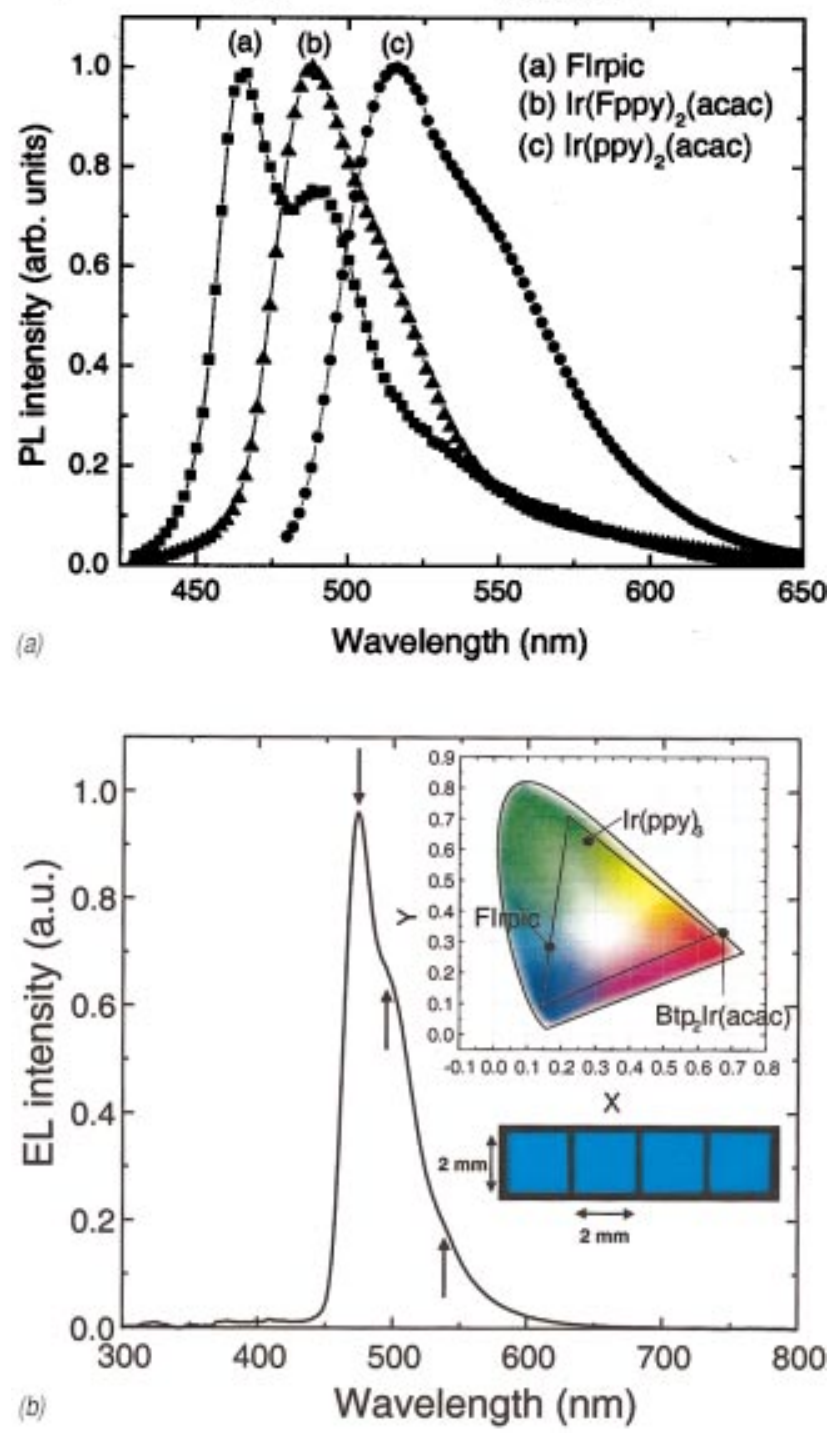

FIG. 1. (Color) (a) Molecular structures of the iridium complexes: $\mathrm{ppy}_{2} \operatorname{Ir}(\mathrm{acac}), \operatorname{FIr}(\mathrm{acac})$, and FIrpic, with their photoluminescence spectra in a dilute $\left(10^{-5} \mathrm{M}\right)$ chloroform solution. (b) Electroluminescence spectra of the following OLED structure: ITO/CuPc $(10 \mathrm{~nm}) / \alpha$-NPD $(30 \mathrm{~nm}) / \mathrm{CBP}$ host doped with $6 \%$ FIrpic $(30 \mathrm{~nm}) /$ BAlq $(30 \mathrm{~nm}) / \mathrm{LiF}(1 \mathrm{~nm}) / \mathrm{Al}(100 \mathrm{~nm})$. The EL spectrum has a maximum at the peak wavelength of $\lambda_{\max }=475 \mathrm{~nm}$ and additional subpeaks at $\lambda_{\text {sub }}=495$ and $540 \mathrm{~nm}$ (arrows), which agrees with the PL spectral shape. (Inset) CIE coordinates of FIrpic $(x=0.16, y=0.29)$, $\operatorname{Ir}(\text { ppy })_{3}(x=0.28, y=0.62)$, and $\operatorname{btp}_{2} \operatorname{Ir}($ acac $)(x=0.67, y=0.33)$, and a color photograph of an array of four FIrpic OLEDs.

change mechanism. First, a 10-nm-thick copper phthalocyanine $(\mathrm{CuPc})$ hole injection layer followed by a 30-nm-thick 4,4'-bis[ $N$-(1-naphthyl)- $N$-phenyl-amino]biphenyl $(\alpha$-NPD) hole transport layer (HTL) were deposited. Next, a 30-nmthick light-emitting layer (EML) consisting of 6\% FIrpic doped into a $4,4^{\prime}-N, N^{\prime}$-dicarbazole-biphenyl (CBP) host was prepared via thermal codeposition. Finally, a 30-nmthick layer of 4-biphenyloxolato aluminum(III)bis(2-methyl-

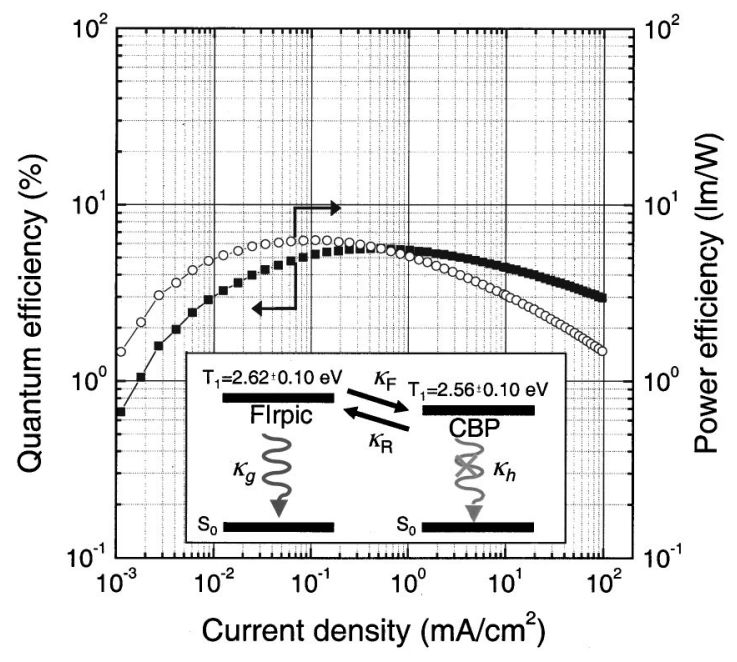

FIG. 2. External electroluminescent quantum ( $\eta_{\text {ext }}$ : filled squares) and power $\left(\eta_{p}\right.$ : open circles) efficiencies of the following OLED structure: ITO/CuPc $(10 \mathrm{~nm}) / \alpha$-NPD $(30 \mathrm{~nm}) / \mathrm{CBP}$ host doped with $6 \%$ FIrpic (30 $\mathrm{nm}) / \mathrm{BAlq}(30 \mathrm{~nm}) / \mathrm{LiF}(1 \mathrm{~nm}) / \mathrm{Al}(100 \mathrm{~nm})$. (Inset) Energy-level diagram of triplet levels of a CBP host and a FIrpic guest. Due to the energy lineup of CBP and FIrpic triplet levels, both extothermic and endothermic transfer is possible. Here, $\kappa_{g}$ and $\kappa_{h}$ are the radiative decay rates of triplets on the guest (phosphor) and host molecules, and the rates of exothermic (forward) $\left(\kappa_{F}\right)$ and endothermic (reverse) $\left(\kappa_{R}\right)$ energy transfers between CBP and FIrpic are also indicated.

8-quinolinato)4-phenylphenolate (BAlq) was used to transport and inject electrons into the EML. A shadow mask with rectangular $2 \mathrm{~mm} \times 2 \mathrm{~mm}$ openings was used to define the cathode consisting of a 1-nm-thick LiF layer, followed by a 100-nm-thick Al layer. After deposition, the device was encapsulated using an UV-epoxy resin under a nitrogen atmosphere with $<1$ ppm oxygen and water. Given that the peak CBP triplet wavelength ${ }^{9}$ is $\lambda=484 \mathrm{~nm}[(2.56 \pm 0.10) \mathrm{eV}]$, compared to $\lambda=475 \mathrm{~nm}[(2.62 \pm 0.10) \mathrm{eV}]$ for FIrpic (see spectra in Fig. 3), endothermic transfer may be interrupted by nonradiative defect states of intermediate energy. Introduction of oxygen or water may be the source of such defects. Indeed, we have found that breaking vacuum at any point in the fabrication process and exposure to air or purified oxygen $(<1$ ppm oxygen and water) results in a decrease in efficiency of at least a factor of 2 below the values reported here. A similar ambient sensitivity is not observed for green and red electrophosphorescence OLEDs employing conventional exothermic energy transfer mechanisms.

Figure 1(b) shows the EL spectrum with a maximum at the peak wavelength of $\lambda_{\max }=475 \mathrm{~nm}$ and additional subpeaks at $\lambda_{\text {sub }}=495$ and $540 \mathrm{~nm}$ (arrows), which generally agrees with the PL spectral shape. The Commission Internationale de L'Eclairage (CIE) coordinates of $(x=0.16$, $y=0.29$ ) for a FIrpic OLED is shown in the inset of Fig. 1(b) along with the coordinates of green $\left[\operatorname{Ir}(\mathrm{ppy})_{3}\right]$ and red $\left[\mathrm{Bt} \mathrm{p}_{2} \operatorname{Ir}(\mathrm{acac})\right]$ electrophosphorescence devices.

Figure 2 shows $\eta_{\text {ext }}$ and $\eta_{p}$ as functions of current density. A maximum $\eta_{\mathrm{ext}}=(5.7 \pm 0.3) \%$ and a luminous power efficiency $\left(\eta_{p}\right)$ of $(6.3 \pm 0.3) \mathrm{lm} / \mathrm{W}$ are achieved at $J=5$ and $0.1 \mathrm{~mA} / \mathrm{cm}^{2}$, respectively. While the device shows a gradual decrease in $\eta_{\text {ext }}$ with increasing current which has previously been attributed to triplet-triplet annihilation, ${ }^{12}$ a maximum luminance of $6400 \mathrm{~cd} / \mathrm{m}^{2}$ with $\eta_{\text {ext }}=3.0 \%$ was obtained even at a high current of $J=100 \mathrm{~mA} / \mathrm{cm}^{2}$. These values compare 


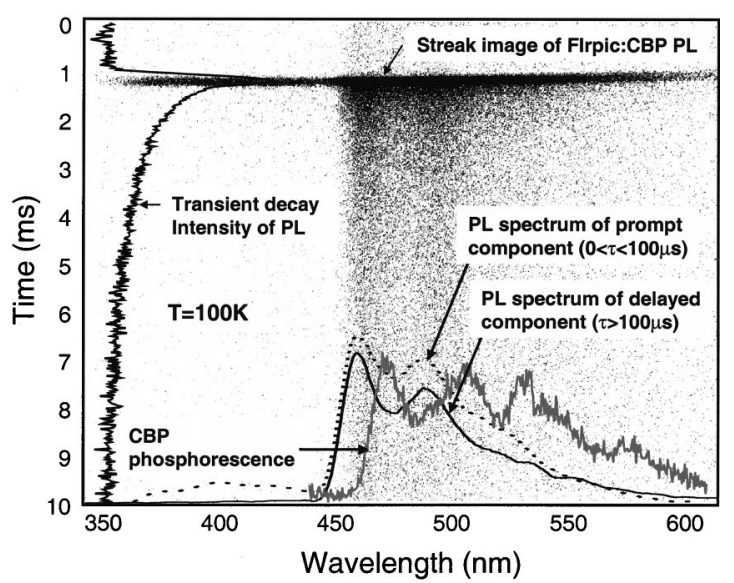

FIG. 3. Streak image of a $6 \%$ FIrpic:CBP film (100 nm thick) on a $\mathrm{Si}$ substrate under nitrogen pulse excitation $(\sim 500 \mathrm{ps})$ at $T=100 \mathrm{~K}$. Two distinct decay processes, prompt and delayed phosphorescence, are demonstrated along with their photoluminescent spectra: dashed line $=$ delayed and solid line $=$ prompt. Also shown is the CBP phosphorescence spectrum obtained at $10 \mathrm{~K}$.

favorably with $\eta_{\mathrm{ext}}=2.4 \%$ for fluorescent devices with a similar blue color emission spectrum. Since the triplet energy level of a CBP host $(2.56 \pm 0.10) \mathrm{eV}$ is slightly less than that of FIrpic at (2.62 \pm 0.10$) \mathrm{eV}$ (inset of Fig. 2), exothermic energy transfer from FIrpic to CBP is inferred. The pronounced roll off at small $J$ is indicative of the sensitivity of backward energy transfer to the presence of energy dissipative pathways, reducing the efficiency via nonradiative triplet recombination when the density of triplets is too low to saturate these parasitic mechanisms.

Figure 3 shows a streak image of the transient decay of a 6\% FIrpic:CBP film at $T=100 \mathrm{~K}$ with two time-resolved emission spectra. In addition to the prompt phosphorescence of FIrpic, we observe an extremely long decay component lasting for $\tau \sim 10 \mathrm{~ms}$, which follows the CBP triplet lifetime. Since the PL spectrum of the slow component coincides with that of FIrpic PL, this supports the conclusion that exothermic energy transfer from FIrpic to CBP occurs. The triplet state then migrates through the CBP host molecules, and finally, is endothermally transferred back to FIrpic, resulting in the delayed phosphorescence observed. Due to the significant difference of lifetimes of the excited states, $\kappa_{h} \ll \kappa_{g},\left(\kappa_{h}\right.$ and $\kappa_{g}$ are the radiative decay rates of the triplets on the host and guest molecules, respectively), the triplet exciton decay originates from FIrpic, as desired. The blue emission centered at $\lambda_{\max }=400 \mathrm{~nm}$ in the prompt emission spectrum is due to fluorescence of CBP, with a transient lifetime $\ll 100$ ns, which is significantly shorter than the decay of FIrpic.

Figure 4 shows the temperature dependence of the transient decay and the relative PL efficiency $\left(\eta_{\mathrm{PL}}\right)$ of FIrpic doped into CBP. After a slight enhancement of $\eta_{\mathrm{PL}}$ as the temperature is increased from 50 to $200 \mathrm{~K}$, it once again decreases at yet higher temperatures. The transient decay characteristics are also temperature dependent. In particular, a significant decrease in the nonexponential decay time was observed at $T=50$ and $100 \mathrm{~K}$. The increase of $\eta_{\mathrm{PL}}$ from

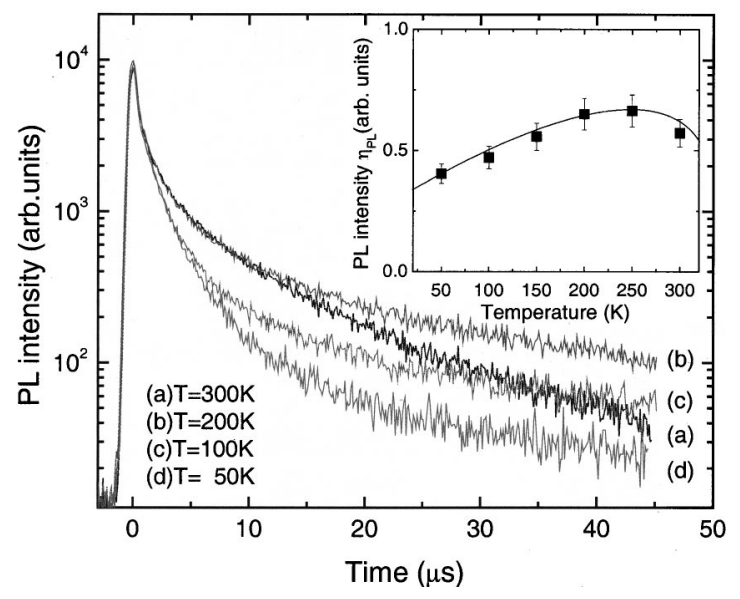

FIG. 4. Transient photoluminescence decay characteristics of a 6\% FIrpic: CBP film (100 nm thick) on a Si substrate under nitrogen pulse excitation $(\sim 500 \mathrm{ps})$ at $T=50,100,200$, and $300 \mathrm{~K}$. (Inset) Temperature dependences of the relative photoluminescence efficiency $\left(\eta_{\mathrm{PL}}\right)$ of the film.

$T=300$ to $200 \mathrm{~K}$ is due to the suppression of nonradiative decay of FIrpic. The decrease below $T \sim 200 \mathrm{~K}$, however, is a signature of retardation of the endothermic process of energy transfer from CBP to FIrpic, leading to loss of the radiative triplet excitons. Since we observe no delayed component at $T=300 \mathrm{~K}$, energy transfer from CBP to FIrpic is very efficient with thermal assistance. In contrast, the PL intensity of $\operatorname{Ir}(\mathrm{ppy})_{3}$ :CBP shows no temperature dependence along with no evidence for such a slow component at low temperature, suggesting the absence of backward energy transfer in that system.

In summary, we demonstrated efficient blue electrophosphorescence using FIrpic as the phosphor molecule. The transient phosphorescence decay suggests the presence of endothermic energy transfer between the phosphor and the conductive CBP host.

This work was funded by the Universal Display Corporation, the Defense Advanced Research Projects Agency, and the Air Force Office of Scientific Research.

${ }^{1}$ M. A. Baldo, D. F. O’Brien, Y. You, A. Shoustikov, S. Sibley, M. E. Thompson, and S. R. Forrest, Nature (London) 395, 151 (1998).

${ }^{2}$ M. A. Baldo, S. Lamansky, P. E. Burrows, M. E. Thompson, and S. R. Forrest, Appl. Phys. Lett. 75, 4 (1999).

${ }^{3}$ C. Adachi, M. A. Baldo, and S. R. Forrest, Appl. Phys. Lett. 77, 904 (2000).

${ }^{4}$ C. Adachi, S. Lamansky, M. A. Baldo, R. C. Kwong, M. E. Thompson, and S. R. Forrest, Appl. Phys. Lett. 78, 1622 (2001).

${ }^{5}$ C. Adachi, M. A. Baldo, M. E. Thompson, and S. R. Forrest, Bull. Am. Phys. Soc. 46, 863 (2001).

${ }^{6}$ M. A. Baldo and S. R. Forrest, Phys. Rev. B 62, 10958 (2000).

${ }^{7}$ W. E. Ford and M. A. J. Rogers, J. Phys. Chem. 96, 2917 (1992).

${ }^{8}$ S. Lamansky, P. Djurovich, D. Murphy, F. Abdel-Razzaq, C. Adachi, P. E. Burrows, S. R. Forrest, and M. E. Thompson, J. Am. Chem. Soc. 123, 4304 (2001)

${ }^{9}$ A. W. Grice, D. D. C. Bradley, M. T. Bernius, M. Inbasekaran, W. W. Wu, and E. P. Woo, Appl. Phys. Lett. 73, 629 (1998).

${ }^{10}$ C. Hosokawa, H. Higashi, H. Nakamura, and T. Kusumoto, Appl. Phys. Lett. 67, 3853 (1995).

${ }^{11}$ C. Hosokawa, M. Eida, M. Matsuura, K. Fukuoka, H. Nakamura, and T. Kusumoto, Synth. Met. 91, 3 (1997).

${ }^{12}$ M. A. Baldo, C. Adachi, and S. R. Forrest, Phys. Rev. B 62, 10967 (2000). 